\title{
INDEXING FINANCIAL REPORTING INFORMATION FOR HERITAGE MANAGEMENT
}

\author{
Nabiela Noaman, Hassan Ouda, Johan Christiaens
}

\section{Introduction}

The way 'Heritage Assets' are preserved is a symbol of a country's civilization (Shan, 2006).

Heritage assets (HA) are of utmost significance to shaping nations' identities. Their significance is derived from their historical, aesthetic, scientific and social values. They should be well preserved to continue offering social benefits for an indefinite period (Barton, 2005). Countries possessing rich legacies of HA should manage them properly to evade negligence and loss of such irreplaceable possessions. Thus, governments are responsible for safeguarding $\mathrm{HA}$ and ensuring their retention for future generations.

HA has been defined broadly by various standard setting bodies (cf. ASB-UK, IPSASB, GASB/FASAB-USA, CICA-Canada, and AASBAustralia, among others). Definitions have constituted a wide range of classifications and characteristics. (Accounting Standards Board [ASB], 2006, p. 18) proposed the following definition for $\mathrm{HA}$; "An asset with historic, artistic, scientific, technological, geophysical or environmental qualities that is held and maintained principally for its contribution to knowledge and culture and this purpose is central to the objectives of the entity holding it".

The governments' role to safeguard HA is ensured by exercising sound practices of heritage management (HM), while facilitating delivery of related services to the community in an efficient and cost-effective way (ICOMOS, 1999). According to the Productivity Commission (2006), greater provision of information about HA tasks and required resources should increase government accountability for public HA conservation. Sufficient information about HA provides guidance for managers in the allocation of scarce funds. The NSW Treasury (2004) has determined HM practices based on five phases which are consistent with practices adopted by several countries including New Zealand, England, and some Australian states as follows: the identification phase, the strategic planning phase, the detailed planning phase, the implementation phase, and the monitoring and review phase. Financial reporting (FR) could be integrated in almost all HM practices, i.e., assessment and recording of $\mathrm{HA}$, planning for governmental resources, identification of responsibilities, discharge of accountability, and assurance of implementation of plans. Moreover, it can effectively facilitate better monitoring and reviewing by using its information to establish asset performance indicators. The Queensland Department of Public Works (2008) asserted that governments should establish such indicators and integrate them with existing asset management practices to guarantee better HM. NSW Heritage Office (1996) elicited that a good practice of HM is attainable with the support of an informative accounting system. The aforementioned system should guarantee a reliable, true, and fair view for the institution position as well as maximize government entities' efficiency, transparency, and accountability. Such incorporation between accounting and management practices contribute to further develop the safeguarding process of HA.

Previous research on accounting for $\mathrm{HA}$ (Barton, 2000; Barton, 2005; ASB, 2006; Lacerra and Stafford, 2009; Wild, 2013; Ouda, 2014) has taken a one dimensional perspective, focusing on examining proper FR approaches and overlooking user-needs. Albeit meeting user-needs is considered the main objective for FR as per a long series of reports (Mayston, 1992). Accounting standards-setting boards are expected to issue standards that help in providing users of government financial reports with useful information for the purpose of making economic decisions. This is based on 
the decision-usefulness theory of accounting for George J. Staubus which was adopted by private sector accounting standards setters and then followed by public sector accounting standards setters with the rise of the NPM. Three main dimensions pertain to the decisionusefulness model: i) users, ii) user information needs and iii) the purposes for which users require information (Mack, 2003). The previous model could be used as a measurement tool to evaluate the quality of the standards, i.e. how accounting standards requirements align with user-needs of FR information.

The common classification of user groups in accounting research comprises two sorts of users groups: dependent-users (externalusers), whom rely on the general-purpose financial reports and non-dependent-users (internal-users), whom have the power to command special purpose financial reports (Australian Accounting Research Foundation [AARF], 1990). Even though, a plethora of literature (Davidson, 1977; Jones et al., 1985; Coy et al., 1997; Steccolini, 2004; Walker et al., 2004; Mack and Ryan, 2006; Aversano and Christiaens, 2014) has affirmed that internal users (internal-management and elected officials) are undeniably the most important users of governmental FR information. To the author best knowledge only one study has investigated FR user-needs of HA. Aversano and Christiaens (2014) investigated user-needs of elected officials in the Italian government and compared them to IPSAS 17's requirements. Internal-Management as a focal group of internal users was overlooked in that study. Henceforth, in our study we will focus on the needs of internal-management as the main user group responsible for safeguarding of $\mathrm{HA}$. We seek to fill the aforementioned gaps in literature by reflecting on the decision usefulness theory in its broad sense, focusing specifically on its first dimension "defining users"; in our case (internal-management) and 2nd dimension "identifying user-needs of FR".

We aim to contribute to user-needs research by investigating the needs of a focal user group namely internal-management which was overlooked in extant research. Moreover we aim to develop a measurement tool that assesses the quality of FR in annual reports from user-needs perception, which should guide governments to the suitable FR approach within the local context. Finally, we aim to bridge the gap between user-needs and accounting standards by comparing the existing accounting standards requirements to HM user-needs. The following research questions are posited accordingly;

RQ1: What sort of governmental FR information does HM require?

RQ2: Which dimensions of FR information are the most significant to HM?

RQ3: To what extent do the accounting standards requirements satisfy HM's FR needs?

To accomplish this aim, we seek to delineate the governmental FR information required by HM users and classify them into groups/dimensions. The empirical investigation has to take place in a country possessing a legacy of HA like Egypt, Greece and Italy thus requiring a good practice of $\mathrm{HM}$. Egypt with around one third of world's HA (Egyptian-stateinformation-system, 2012) has been chosen for the empirical investigation. We then assess the significance of the deduced dimensions to the management practice. In addition, we test the content and construct validity of the dimensions to assure that they represent appropriately the underlying FR information. Fig. 1 reflects the identified research gaps and the study contributions linked to the research questions.

Subsequently, the current study contributes to our knowledge by developing a FR index for $\mathrm{HM}$ and ranking the dimensions based on significance to users. Moreover, the study reveals the deficiencies of the accounting standards requirements with regards to FR needs of $\mathrm{HM}$ by conducting a comparison between the identified FR information in the current research and the accounting standards requirements.

The rest of this study comprises four sections: the second section establishes the main building blocks of FR of HA and discusses the rationale of the FR dimensions used in extrapolation and utilized to develop the desired index. The third section presents the adopted research methodology for the study, and the fourth section demonstrates the results and findings of the empirical investigation. Finally, the fifth section concludes.

\section{Financial Reporting for $\mathrm{HM}$}

The prime objective of $F R$ is to respond to user-needs (Davidson, 1977; Sutcliffe, 2003), 


\section{Fig. 1: Research gaps and contributions}

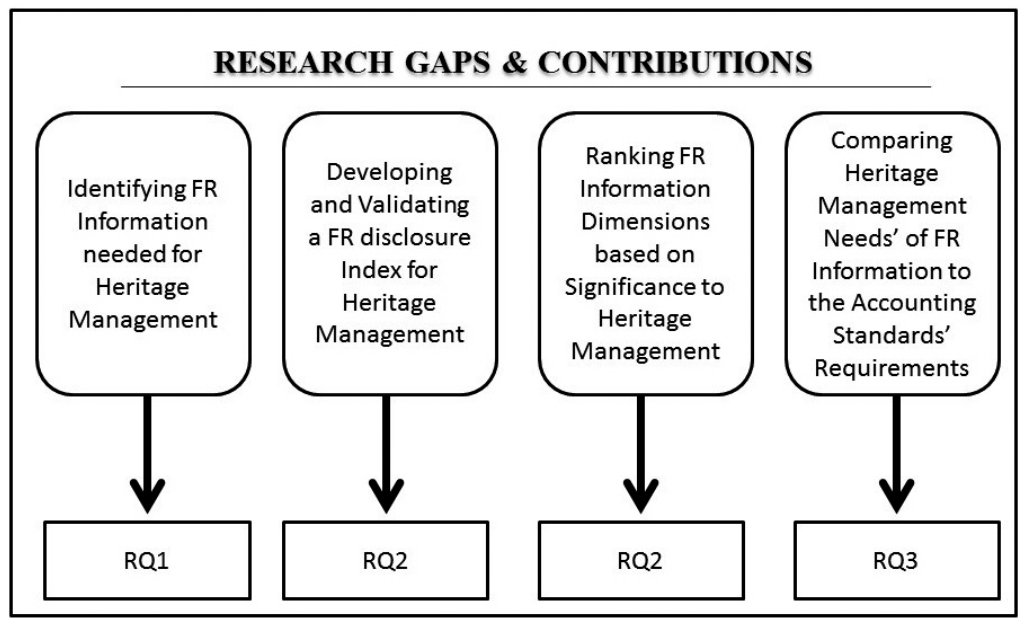

Source: own

providing useful information to a wide range of users (Wild, 2013). This is affirmed in a long series of reports (Mayston, 1992). Nevertheless, public sector standard-setting bodies are criticized for the disinterest of users in financial reports. Research has revealed that accounting standards did not conform to user-needs (Walker et al., 2004; Mayston, 1992; Jones \& Puglisi, 1997; Barton, 1999; Mack, 2003; Sutcliffe, 2003). According to AARF (1990), general-purpose financial reports should provide useful information for decision-making and management discharge of accountability. This is by disclosing information about: i) performance, ii) financial position, and iii) financing and investing of the reporting entity, including information about compliance. ASB (2006) has specified HA reporting requirements of 10 standard-setting bodies, comprising 13 standards. The requirements of these standards could be summed up as follows: i) Recognition requirements: the majority of the standards required recognition in either income statements (in the case of adopting a noncapitalization approach) or balance sheets (in the case of adopting a capitalization approach) whilst measurement is not possible, HA are to be reported in footnotes. ii) Measurement requirements: the mainstream of the standards require using the cost or valuation models in the case of adopting the capitalization approach and if measurement is feasible. iii) Disclosure requirements: conventionally regular disclosures of property, plant and equipment are required for recognized HA, whilst detailed comprehensive descriptions are required for unrecognized $\mathrm{HA}$, including; age, nature, scale of assets, use, quantification of physical units, condition of asset, maintenance, disposal, details to any significant changes to the collection during the fiscal period and all other relevant policies.

User-needs research in this domain revealed different user-needs information including; highly detailed disclosure, narrative, performance and accountability information. (Robbins, 1984; Hay \& Antonio, 1990; Lee \& Fisher, 2004; Mack \& Ryan, 2006; Barker, 2006; Lacerra \& Stafford, 2009; Aversano \& Christiaens, 2014). Furthermore, Aversano and Christiaens (2014) have affirmed that users are particularly interested in information about management, protection, conservation and maintenance of HA to support decision- 
making and discharging of accountability. Accordingly, the requisite FR information could be amalgamated in five dimensions as follows:

\subsection{Recognition and Measurement (Valuation)}

Extant research (Carnegie \& Wolnizer, 1995; Barton, 2000; Greenwood, 2015; Ellwood 2016) has extensively investigated the appropriateness of the inclusion of HA in the financial statements, a debate that is still ongoing. The recognition and financial valuation of $\mathrm{HA}$ endure enormous costs and efforts. It is crucial then to investigate the necessity of obtaining such kind of information. In this study we go beyond the regular debate of the whether or not it is appropriate to evaluate HA and we focus on investigating the significance of this dimension to HA managers. The recognition and measurement dimension is considered the first building block of FR of HA (Aversano \& Christians, 2014), thus it as the first dimension in our hypothesized FR of HA index which sought to be examined.

\subsection{Disclosure}

Lately, there has been a call for enhanced disclosure of information related to $\mathrm{HA}$ due to the complexity of recognition and valuation of HA (Lacerra \& Stafford, 2009; ASB, 2006). Aversanno and Christians (2014) has assumed that a more comprehensive disclosure of financial and non-financial information related to HA would satisfy the needs of public accountability and NPM. Opt-cit. (2014) has included 'disclosure' as one of the main building blocks of $\mathrm{FR}$ of $\mathrm{HA}$ after investigating its significance to politicians. In this study, we will investigate the significance of this dimension for $\mathrm{HM}$, postulating it as the 2nd dimension in our hypothesized FR of HA index.

\subsection{Performance Information}

The third building block of FR of HA is the performance related information. Previous normative and empirical research (Sharp \& Carpenter, 1998; Carlin \& Guthrie, 2001; Mack, 2003; Walker et al., 2004; Barton, 2005) have affirmed that users of public sector general purpose financial reports place most emphasis on performance information. Lacerra and Stafford (2009) stated that managers need this kind of information to assess efficiency and effectiveness of performed activities. It allows managers to make better comparative analysis across different periods and similar entities and to have better surveillance on HM operations, detecting points of weaknesses and strengths. Thus, we postulated this dimension as the 3rd one in our FR index for HM.

\subsection{Accountability}

HA are public, not for sale, and "inalienable" assets which are funded by governments or private donations (Barton, 2000). For that, ASB (2006) has affirmed that provision of information, which assists the assessment of entities' stewardship, is a must. Discharging of financial and public accountability is one of the main reasons; users require governmental financial information (Steccolini, 2004; Mack \& Ryan, 2006). Many scholars supported this argument with evidence from empirical research (Jones et al., 1985; Jones \& Puglisi, 1997; Mignot \& Dolley, 2000). According to AARF (1990), financial information is further used by users to assess the ability of the entity to continue to provide goods and services in the future. For these reasons, accountability related information construct a significant measure of proper FR and by which internal management can discharge accountability. Subsequently, 'Accountability' could be considered as one of the main building blocks of FR and we postulate it as the 4th dimension in our index.

\subsection{Narrative}

Increasing attention is paid to narrative reporting; it is considered a crucial element in achieving quality reporting (Beattie et al., 2004). Narrative information is high quality descriptive explanations included in annual reports which are expected to satisfy the changing information needs of internal and external users. Aversnao and Christiaens, (2014) has included 'Narrative' as one of the main building blocks of FR of HA. In this study, we postulate 'Narrative' information as the fifth dimension in our index.

Fig. 2 summaries the five building blocks/ dimensions of our FR index for HM. Certainly, this proposed model cannot convey a holistic approach for FR of HA, but rather attempts to elucidate the basic needs of an important group of internal users (Management) whom are the main the responsible party for the safeguarding of $\mathrm{HA}$. 


\section{Fig. 2: Hypothesized dimensions for FR index for HM}

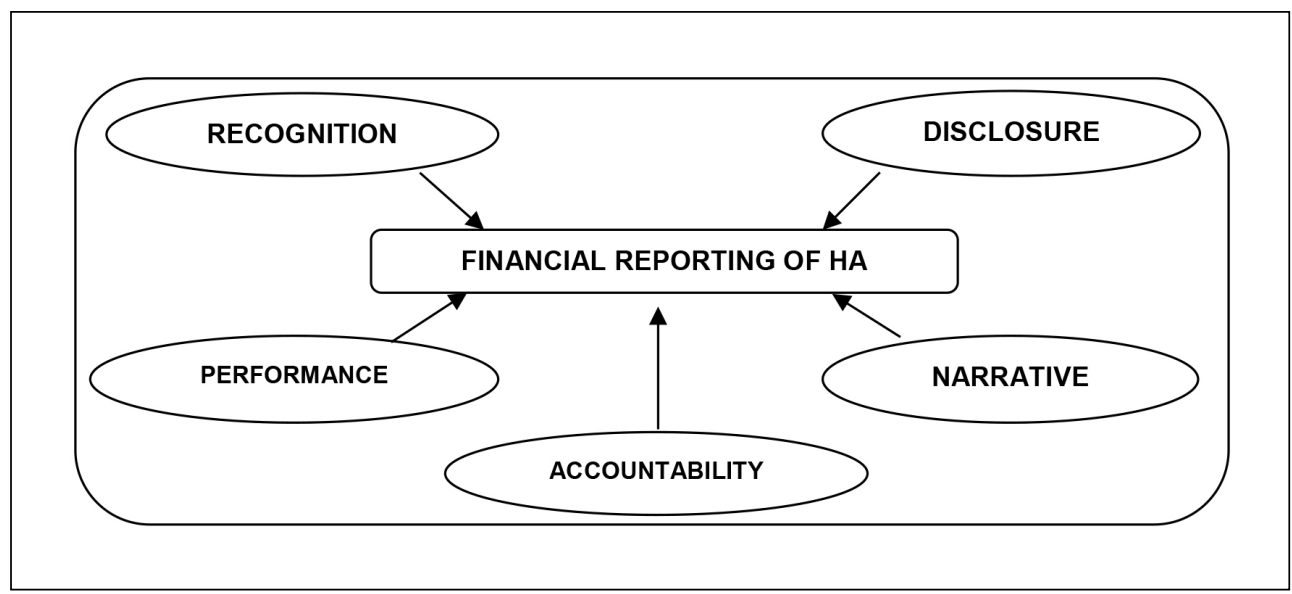

Source: own

Albeit the fact that during the past decades, researchers attempted to measure the relative importance to users and/or extent of disclosure of financial information in annual reports by developing disclosure indices e.g. (Buzby, 1974; Coy et al., 1997; Stanley et al., 2008), until now none has investigated if FR of heritage assets fulfils the needs of HM. This might be owed to the relative novelty of accounting for $\mathrm{HA}$ and $\mathrm{HM}$ research. Therefore, there is a gap in research that should be filed by further investigation and research. For that reason, one of the concerns of this study is to develop and validate a measurement tool "disclosure index" that denotes the most importance FR information for the HM practice. Subsequently, the motive for operationalizing this disclosure index could be framed as; i) to investigate what are the basic FR information needed by $\mathrm{HM}$; ii) to measure the extent of disclosure of important $\mathrm{FR}$ information for $\mathrm{HM}$ in annual reports.

According to Christiaens (2003), index construction methodology is a term used by Coy et al. (1997) to describe the procedures followed to design measurement instruments. Such instruments are designed to measure a series of items that indicates a level of disclosure, compliance, or accountability. Indices, scales or any measurement instrument are usually developed to assess a certain construct and investigate the underling dimensions/factors.
Marston and Shrives (1991) affirms that the first step of constructing a disclosure index, dictate making a selection of items since the number to be disclosed might be very large. He also specified that the items selection should be based on the specification of a certain user group, as the interests of user groups vary. Item generation/selection is considered the most important part of developing sound measures. Its prime focus is to establish the content validity of the latent constructs (Kayaly \& Taher, 2010).

In this study, we developed an initial index of 35 items of FR information (Tab. 1). The items/variables underlying the hypothesized dimensions (discussed above) are deduced from the requirements of $\mathrm{HA}$ accounting standards (FRS 15, IPSAS 17, FAS 116, FAS 93, SFFAS 29, FRS 3, and AASB 116) and to user-needs literature (Robbins, 1984; Arcelus \& Trenholm, 1989; Hay \& Antonio, 1990; Mayston, 1992; Barth \& Clinch, 1998; Barton, 2000; Lee \& Fisher, 2004; Mack, 2003; Barker, 2006; Lacerra \& Stafford, 2009; Aversano \& Christiaens, 2014). The selection of the items is based on the following criteria.

1. Commonalities/Concurrence: selected items should be required by mainstream of accounting standards or frequently repeated in user-needs literature.

2. Understandibility: according to ASB (2006, p. 37) "the desirable requirements for FR 


\begin{tabular}{|c|c|c|c|}
\hline DIMENSION & ITEMS* & $\begin{array}{l}\text { Users' } \\
\text { Needs }\end{array}$ & $\begin{array}{c}\text { Accounting } \\
\text { Standards } \\
\text { Require- } \\
\text { ments }\end{array}$ \\
\hline \multirow[t]{12}{*}{ DISC. } & Custody costs of HA & $\sqrt{ }$ & \\
\hline & HA operating expenses & $\sqrt{ }$ & $\sqrt{ }$ \\
\hline & Postponed (deferred) expenses & $\sqrt{ }$ & $\sqrt{ }$ \\
\hline & Allocation and uses of $\mathrm{HA}^{\prime}$ funds & $\sqrt{ }$ & $\sqrt{ }$ \\
\hline & Estimated life of HA & $\sqrt{ }$ & $\sqrt{ }$ \\
\hline & Depreciation value of HA & $\sqrt{ }$ & $\sqrt{ }$ \\
\hline & Depreciation methods of HA & $\sqrt{ }$ & $\sqrt{ }$ \\
\hline & The net exchange differences & $\sqrt{ }$ & $\sqrt{ }$ \\
\hline & Revaluation method used & $\sqrt{ }$ & $\sqrt{ }$ \\
\hline & Date of the revaluation & $\sqrt{ }$ & $\sqrt{ }$ \\
\hline & Changes in valuation criteria & $\sqrt{ }$ & $\sqrt{ }$ \\
\hline & Estimated costs & & $\sqrt{ }$ \\
\hline \multirow[t]{10}{*}{ NARR. } & Funding resources & & $\sqrt{ }$ \\
\hline & Financial value of HA retained from active use and held for disposal & & $\sqrt{ }$ \\
\hline & Restoration, maintenance and conservation plans & $\sqrt{ }$ & \\
\hline & Temporarily idle of HA & & $\sqrt{ }$ \\
\hline & Summary of entities operations & $\sqrt{ }$ & $\sqrt{ }$ \\
\hline & Physical condition of HA & $\sqrt{ }$ & $\sqrt{ }$ \\
\hline & Restrictions on $\mathrm{HA}$ & & $\sqrt{ }$ \\
\hline & Description of HA & $\sqrt{ }$ & $\sqrt{ }$ \\
\hline & Policies for the conservation, restoration etc & $\sqrt{ }$ & $\sqrt{ }$ \\
\hline & Event after financial statement date & $\sqrt{ }$ & \\
\hline \multirow[t]{6}{*}{ PERFO. } & Objective of financial provisions (reserves) & $\sqrt{ }$ & \\
\hline & Extent financial provisions (reserves) achieved its objectives & $\sqrt{ }$ & \\
\hline & Financial and managerial performance & $\sqrt{ }$ & \\
\hline & Compare the results with previous years & $\sqrt{ }$ & \\
\hline & Variance between budgets and actual results & $\sqrt{ }$ & \\
\hline & Financial summary of the past 5 years & $\sqrt{ }$ & $\sqrt{ }$ \\
\hline \multirow[t]{4}{*}{ ACCOU. } & Financial capability to cover short term liabilities & $\sqrt{ }$ & \\
\hline & Financial capability to cover long term liabilities & $\sqrt{ }$ & \\
\hline & Adherence to budget & $\sqrt{ }$ & \\
\hline & Appropriate use for public money & $\sqrt{ }$ & \\
\hline \multirow[t]{3}{*}{ REC. } & Financial value & $\sqrt{ }$ & $\sqrt{ }$ \\
\hline & Valuation methods & $\sqrt{ }$ & $\sqrt{ }$ \\
\hline & Cost of valuation & $\sqrt{ }$ & \\
\hline
\end{tabular}

*Sources: Robbins, 1984; Trenholm \& Arcelus, 1989; Hay \& Antonio, 1990; Mayston, 1992; Barth \& Clinch, 1998; Barton, 2000; Lee \& Fisher, 2004; Mack \& Ryan, 2004; Barker, 2006; Lacerra \& Stafford, 2009; Aversano \& Christiaens, 2014, and FRS 15, IPSAS 17, FAS 116, FAS 93, SFFAS 29, FRS 3, AASB 116

Note: DISC.: Disclosure, NARR.: Narrative, PERFO.: Performance, ACCOU.: Accountability and REC: Recognition \& Measurement. 
of heritage assets entail the provision of relevant and reliable financial information which is readily understandable to users".

3. Comparabilty: selected items should be prepared on a consistent basis and there is no subjectivity in preparing them to allow comparison between accounting periods and between similar entities and which helps in the assessment of the entity's stewardship.

4. Objectivity: can be clearly and accurately measured.

\section{Research Methodology}

Governmental administrative bodies are sought to comply with accounting standards' requirements to provide users with requisite FR information. However, there is uncertainty about the adequacy of these requirements. This concern is raised in extant research c.f. (Sutcliffe, 2003; Christiaens, 2004; CPA Australia, 2006; IFAC, 2006) and affirmed by empirical research c.f. (Aversano \& Christiaens, 2014). This study seeks to investigate this matter further, mainly concentrating on the adequacy of the accounting standards requirements with respect to HA from a managerial perspective. As indicated earlier a FR disclosure index for HM is sought to be developed. The index should comprise the most significant FR information for the management practice, which should help in the decision making process and the management discharge of accountability. The index serves as a reference for the financialreports preparers, guiding them to the FR information that should be presented in the financial reports for the sake of HM. Weightings of the index items are determined by conducting surveys among relevant user groups, asking them about the importance of each item (Marston \& Shrives, 1991). In this study we use the weightings to decide which items to be included in the index and which are to be excluded. The index could be employed later to assess the level of disclosures of essential FR information for HM made by local government authorities in annual reports. For this index we use a simple binary scoring scheme which is often used with this kind of disclosure indices (Beattie et al., 2004; Marston \& Shrives, 1991), whereby the presence or absence of an item is recorded.

The empirical investigation is conducted in the country context of Egypt; a country with an exceptional legacy of cultural heritage. According to the Egyptian-state-informationsystem (2012), Egypt's heritage constitute around one third of the world's HA. The country possess HA with substantial historical significance on the local and international side. Egypt's government is striving to pursue modern HM practices supported by international organizations, e.g. UNESCO. The assessment of the HM FR needs in Egypt can present a good exemplar for the FR needs of HM worldwide. The fact that Egypt is adopting cash accounting in its central and local government does not interfere with our investigation. The adoption of a certain accounting regimes does not coerce adopting same regimes in accounting for HA. Some countries follow full accrual basis yet they do not adopt the capitalization approach for accounting for HA. The results of the study could be used as guideline for the selection of appropriate accounting treatment of HA. Hence, Egypt presented an excellent ground for our empirical investigation.

The research community for this study comprises two groups; the first group includes academics with practical experience of $\mathrm{HM}$. The second group includes HM practitioners comprising: Egyptian Supreme Council of Antiquities (SCA) government officials and professional expatriates. The latter comprises the members of foreign missions who work in collaboration with the SCA to conserve HA. The government officials comprise senior level management as well as lower level management. The higher-level managers would have more insight about strategies and plans, whilst the lower-level managers would have more insight about day to day practice and technical problems. As per Egyptian law no. 117 of 1983, the SCA is granted exclusive authority over all activities related to antiquities within the Egyptian borders on both the central and local government levels. A random sample from each cluster is selected with a sample size larger than 30 to assure normal distribution, according to the theory of the central limit theorem (Rosenblatt, 1956). The previous section of this study has demonstrated how the deductive approach is used to develop an initial index of 35 items for FR of HA presenting five FR dimensions. Henceforth, it is aim to empirically examine the hypothesized dimensions and their underlying information items (variables). The following steps demonstrate how the 
mixed methods (qualitative and quantitative approaches) are utilized to serve answering the research questions.

\subsection{Qualitative Research}

It is acknowledged that expert judgment is of utmost importance in assessing content validity of a research instrument (Kayaly \& Taher, 2010). Consequently, a qualitative research is carried out, aiming at: 1- assessing content validity of the theoretically developed index; 2- contributing in answering the 1st $R Q$; 3- reducing index items to facilitate better response in the empirical investigation. Semistructured in-depth interviews are conducted with public sector accounting professors and senior HM officials in the Egyptian Ministry of Antiquities. The interview questions are based on the 35 items deduced from literature. The public sector accounting professors are pursued to assess content validity of the index items and dimensions, whilst HM experts are interrogated to clarify if the index covers all HM needs of FR. Interviews have been conducted until data stabilized and no new insights are noted. All provided remarks and recommendations are noted and the index is modified accordingly.

\subsection{Quantitative Research}

The aim of this step is to assess the significance of FR information for $\mathrm{HM}$ and to test the validity of the hypothesized index. Subsequently a questionnaire is developed and administered to the targeted population to collect their feedback on the index. This is a common approach in accounting research to develop disclosure indices, where surveys are used to assess the degree of importance of constructed index items (Buzby, 1974). The quantitative analysis is performed on three stages; The first stage contributes along with the conducted qualitative research at empirically answering $R Q 1$, aiming at identifying the significant FR information for HM. Descriptive statistics analysis is conducted including calculations of Mean, Standard Deviation, Coefficient of Variation (CV), and Relevance Importance index (RII) of the index items. CV is the measure of dispersion of responses i.e. it measures the level of homogeneity in responses and is measured by ( $C V=S D / M e a n)$. Whilst RII aims at ordinally arranging variables in terms of importance, i.e., assessing the significance of each item in the index and assessing the dimension with highest significance.

$$
R I I=\sum W / A^{*} N
$$

where $\sum W$ is the sum of weights (ranging from 1 to 5) given to each variable (information item) by all respondents; $A$ is the highest weight (5 in this case); and $N$ is the total number of respondents.

The second stage addresses RQ2, which is assessing the significance of the hypothesized FR dimensions for $\mathrm{HM}$ and to validate the hypothesized FR of HA disclosure index. To achieve this, the dimensions are validated using confirmatory factor analysis (CFA) to assure that they represent the underlying FR information well. Subsequently they are ranked based on significance to users. This validation technique has been suggested in previous public accounting research (Mack, 2003; Sharifabadi, 2012) to confirm a hypothesised construct/dimension structure. It is commonly used to assess reliability of measurement tools. e.g., index and scales (Churchill, 1979; Abu Youssef, 2011). The third stage addresses RQ3 by comparing the validated $\mathrm{FR}$ dimensions for HM and the relevant accounting standards requirements. This helps in revealing whether the accounting standards requirements respond to the FR needs of $\mathrm{HM}$ or not. The following diagram, (Fig. 3) briefly outlines the research methodology adopted for the entire study.

The FR of HA index comprised the five dimensions previously discussed in the section II. A survey approach (questionnaire) is used with a five-point Likert scale is used; $(1=$ "not at all important" to $5=$ "extremely important"). The questionnaire also included questions about demographic data including position in organization, experience and background in HM, which are measured by different scales. Survey questionnaires are disseminated via various techniques online by inviting target groups, emails, and self-administered questionnaires. Prior to actual administration of the questionnaire, a pilot test is performed with a random sample of population (fifteen participants) to ensure the structure of questionnaire, language, length as well as time needed to fill it out. During the piloting phase, verbal protocol analysis is utilized whereby the respondents are asked to give oral feedback while reading the questionnaire. There were 


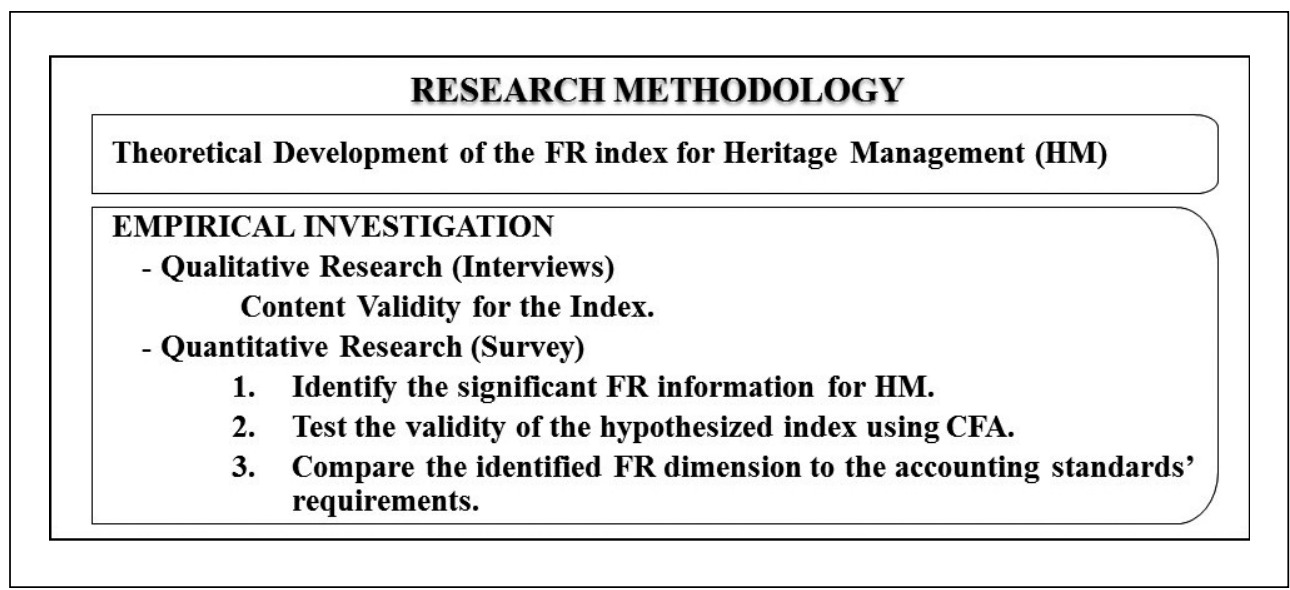

Source: own

no major comments and the index is modified based on participants' feedback.

\section{Results and Analysis}

The following section demonstrates the results of the empirical investigation (interviews and questionnaires). SPSS and AMOS software are used in the statistical analysis.

\subsection{Analysis of Responses}

A total of 600 questionnaires were distributed among the prescribed sample, out of which 350 were sent by direct emails and 250 were sent as hard-copies. The collected questionnaires amounted to 191 out of which 158 were valid and 33 were incomplete. The total response rate is $31.8 \%$ and particularly $26.3 \%$ after deducting the incomplete questionnaires. This percentage corresponds favourably to the response rate of similar studies (Jones et al., 1985; Priest et al., 1999; Coy et al., 1997; Mack \& Ryan, 2003; Aversano \& Christiaens, 2014). Tab. 2 reports the breakdown of the response rates of the survey from both expert practitioners and academics with practical HM experience.

\subsection{Reliability}

A reliability test is conducted, indicating that the items have relatively high internal consistency. Cronbach's Alpha coefficient is estimated at 0.895 .

\subsection{Qualitative Research}

The interrogation of interviewees provided insights and deep understanding of the potential respondents' perception, i.e. enabling the researcher to see things the same way as the respondents (Daymon \& Holloway, 2010). The recommendations included advices to merge items together so as to avoid replication, few items are required to be removed, due to subjectivity, complexity and low understandably by targeted population and ultimately no additional items are required to be added. The index at the outset included 35 items and after the advised modifications it is reduced to 26 items, the new hypothesized index is presented below in (Tab. 3). The index is considered a simple disclosure index, which means that all items included have an equal and fixed weight on the index (Christiaens, 1999). The items are classified based on the previously discussed five dimensions; i) recognition and measurement (valuation); ii) disclosure; iii) narrative; iv) performance and v) accountability.

\subsection{Quantitative Research \\ Stage One: Descriptive Statistics}

The descriptive statistics is used to complement the qualitative research aiming to answer the RQs. First, the results of the coefficient of variation (CV) revealed that 8 variables, namely (Var.06, Var.07, Var.08, Var.09, Var.11, Var.24, 
Analysis of responses

\begin{tabular}{l|c|c|c|c} 
SAMPLING UNIT & $\begin{array}{c}\text { DISTRIBUTED } \\
\text { QUESTIONNAIRES }\end{array}$ & $\begin{array}{c}\text { COLLECTED } \\
\text { QUESTIONNAIRES }\end{array}$ & $\begin{array}{c}\text { VALID } \\
\text { QUESTIONNAIRES }\end{array}$ & $\begin{array}{c}\text { RESPONSE } \\
\text { RATE }\end{array}$ \\
\hline ACADEMICS & 200 & 79 & 64 & $32.0 \%$ \\
\hline PRACTITIONERS & 400 & 112 & 94 & $23.5 \%$ \\
\hline TOTAL & 600 & 191 & 158 & $26.3 \%$ \\
\hline
\end{tabular}

\begin{tabular}{|c|c|c|}
\hline DIMENSION & VAR \# & ITEMS* \\
\hline \multirow[t]{7}{*}{ DISC. } & Var.01 & Custody costs of HA \\
\hline & Var.02 & HA operating expenses \\
\hline & Var.03 & Postponed (deferred) expenses \\
\hline & Var.05 & Allocation and uses of $\mathrm{HA}^{\prime}$ funds \\
\hline & Var.06 & Estimated life of HA \\
\hline & Var.07 & Depreciation value of $\mathrm{HA}$ \\
\hline & Var.08 & Depreciation methods of HA \\
\hline \multirow[t]{7}{*}{ NARR. } & Var.04 & Funding Resources \\
\hline & Var.09 & Financial value of HA retained from active use and held for disposal \\
\hline & Var.10 & Restoration, maintenance and conservation plans \\
\hline & Var.11 & Temporarily idle of HA \\
\hline & Var.12 & Summary of entities operations \\
\hline & Var.13 & Description \& Physical condition of HA \\
\hline & Var.14 & Policies \& Restrictions on HA \\
\hline \multirow[t]{5}{*}{ PERFO. } & Var.15 & Objective of financial provisions (reserves) \\
\hline & Var.16 & Extent financial provisions (reserves) achieved its objectives \\
\hline & Var.17 & Financial and managerial performance compared to previous years \\
\hline & Var.18 & Variance between budgets and actual results \\
\hline & Var.19 & Financial summary of the past 5 years \\
\hline \multirow[t]{4}{*}{ ACCOU. } & Var.20 & Financial capability to meet short term liabilities \\
\hline & Var.21 & Financial capability to meet long term liabilities \\
\hline & Var.22 & Adherence to budgets \\
\hline & Var.23 & Appropriate use of public money \\
\hline \multirow[t]{3}{*}{ REC. } & Var.24 & Financial value of $\mathrm{HA}$ \\
\hline & Var.25 & Valuation methods \\
\hline & Var.26 & Cost of valuation \\
\hline
\end{tabular}

*Sources: Robbins, 1984; Trenholm \& Arcelus, 1989; Hay \& Antonio, 1990; Mayston, 1992; Barth \& Clinch, 1998; Barton, 2000; Lee \& Fisher, 2004; Mack \& Ryan, 2004; Barker, 2006; Lacerra \& Stafford, 2009; Aversano \& Christiaens, 2014, and FRS 15, IPSAS 17, FAS 116, FAS 93, SFFAS 29, FRS 3, AASB 116

Note: DISC.: Disclosure, NARR.: Narrative, PERFO.: Performance, ACCOU.: Accountability and REC: Recognition \& Measurement. 
Var.25 and Var.26) had high (CV) scores; ranging between $40.5 \%$ and $46.4 \%$. This indicates low homogeneity in the responses of those items/ variables compared to the rest of the index items. In other words, this means that the opinions of the respondents varied highly in regard to those items, demonstrating no consensus on their significance. The 8 variables were associated with valuation, depreciation and idle of HA. Second, the results of the Relevance Importance index (RII) demonstrated that the same 8 variables hold the lowest RII scores (34.8-41.4\%), assuring its low significance to HM. The MEAN scores for these 8 variables were; (1.71-2.07), where (1 = "not at all important", 2 = "not important", 4 = "important", and 5 = "extremely important"). Conversely, the other 18 items had a high (RII) scores; (76.5-89.2\%) and MEAN scores; (3.82-4.46), indicating high significance to HM.
(Tab. 4 in Appendix) demonstrates the results of the descriptive statistics.

Hence it could be concluded that the above mentioned 8 variables, highlighted in (Tab. 4 in Appendix) are significantly less important compared to the other FR information items. The results emphasize that the valuation of $\mathrm{HA}$ or asserting a certain life time to HA whom have survived for thousands of years is considered unreasonable. This corresponds positively to the notion that the value of HA is not only to be assessed by its physical characteristics and uniqueness but also by its historical and cultural associations to present, which is certainly is beyond valuation (Wild, 2013). Barton (2009), assert the latter argument as he believes that it is almost unfeasible to obtain a meaningful and reliable financial valuation for $\mathrm{HA}$ and even if obtained, it might not be relevant for a good

\section{Fig. 4: Path Diagram for the hypothesized FR INDEX for HM}

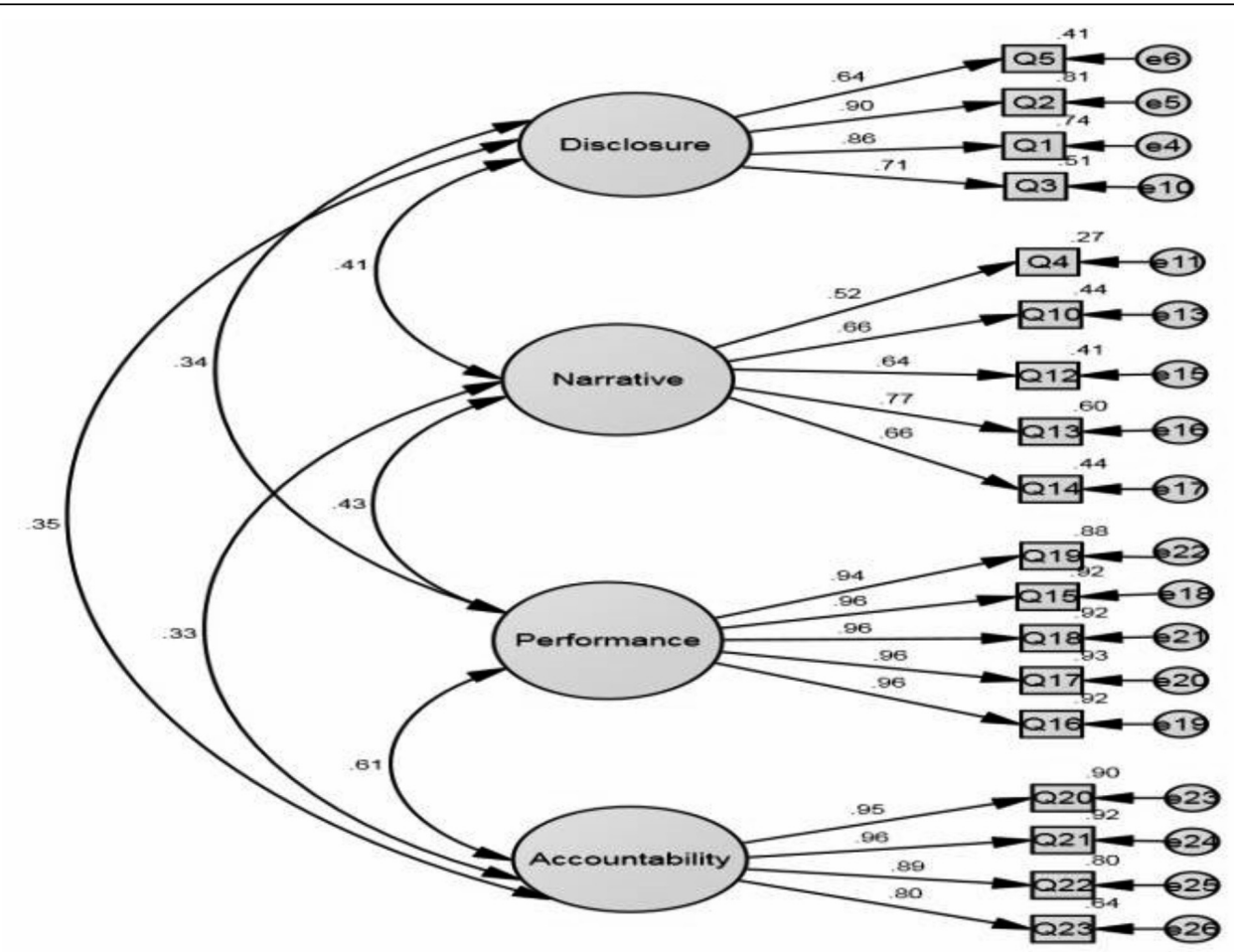

Source: own 
management practice. Thus, the 3 variables underlying the fifth dimension "recognition and measurement" and 5 other variables from the "disclosure" and "narrative" dimensions falls out due to their insignificance to the HM practice. Whilst, the other 18 Items of the hypothesized index are proved significant to HM. Those 18 significant variables underlies four dimensions out of the initial five dimensions; disclosure, performance, accountability and narrative.

\section{Stage Two}

This stage comprises 2 steps; i) testing of the construct validity of the FR for HA index using the confirmatory factor analysis and ii) ranking the FR dimensions based on significance to HM.

\section{I - Validation of the Index Using Confirma- tory Factor Analysis}

The results of the first stage indicate that four FR dimensions of $\mathrm{HA}$; namely performance, accountability, disclosure and narrative are significant for HM. In this stage we needed to test the construct validity of those dimensions using the confirmatory factor analysis (CFA). In other words, to test if each FR dimension represents its underlying items. AMOS software is used to run the CFA, after assuring that its underlying assumptions are met. (Fig. 4) demonstrate the path diagram for the hypothesized index, which was initially deduced from literature and tested qualitatively and quantitatively.

The results of the CFA indicate that the regression weights of the hypothesized index are all found significant (Tab. 8 in Appendix). In addition, the R2 corresponding to observed variables of all three dimensions indicate that the respective dimension explains a respectable portion of the variance (between $27 \%$ and $92 \%)$. This means that the variables correlate positively with their relative dimension, i.e. the FR dimensions represent appropriately its underlying items. Only the "Narrative" Dimension had relatively poor indicators/variables with standardized regression weights ranging from 0.52 to 0.77 and $\mathrm{R} 2$ ranging from 0.27 to 0.6 . This means that some variables correlate weakly with their dimension. Nevertheless no variables are purged since all standardized regression weights were above 0.5 . Ultimately, the results of the CFA indicate that the hypothesized index has good fit. As shown in (Tab. 5), the results are within the general acceptable ranges. This indicates that the collected data confirms the structure of the hypothesized index. I.e. there is a good fit between our hypothesized index and the patterns observed in these data. That is to say, the FR Index dimensions represent appropriately the underlying FR information.

In view of the above results of the CFA, the four hypothesized FR dimensions for $\mathrm{HM}$, namely; the disclosure, performance, and accountability and narrative dimensions are validated. Consequently the FR index for $\mathrm{HM}$ is validated and considered a reliable measurement tool (Tab. 6). This index should direct financial reports preparers to HM userneeds and could be used later to assess the degree of compliance of reporting entities.

\section{II - Assessing the Significance of the FR Dimensions}

The subsequent step in stage two is the ordering of the validated FR dimensions based on significance to HM. The results are shown in (Tab. 7). The tested FR index for HM comprises four dimensions; disclosure, performance, accountability and narrative, whilst the recognition and measurement dimension is excluded for its insignificance to HM. The results, demonstrated in (Tab. 7), reveal that the accountability dimension scored the highest

\section{Tab. 5: Indices of fit for the hypnotized index}

\begin{tabular}{|c|c|c|c|c|c|c|}
\hline & CMIN/DF & CFI & NFI & RMSEA & GFI & AGFI \\
\hline RESULTS & 1.42 & 0.98 & 0.95 & 0.52 & 0.91 & 0.85 \\
\hline \multirow{3}{*}{$\begin{array}{l}\text { ACCEPTABLE } \\
\text { RANGES }\end{array}$} & \multirow{3}{*}{ Less than 3} & Range 0-1 & Range 0-1 & \multirow{3}{*}{ Less than 0.08} & More & More \\
\hline & & More than 0.9 & Perfect fit & & than 0.9 & than 0.8 \\
\hline & & & (NFI of 1$)$ & & & \\
\hline REFERENCES & \multicolumn{6}{|c|}{ Azam et al. (2013), Hair et al. (2006), Chin and Todd (1995) } \\
\hline
\end{tabular}


Tab. 6: Tested and validated index of FR of HA (18 items)

\begin{tabular}{|c|c|c|c|c|}
\hline DIMENSION & VAR \# & ITEMS* & $\begin{array}{l}\text { Users' } \\
\text { Needs }\end{array}$ & $\begin{array}{l}\text { Accounting } \\
\text { Standards } \\
\text { Requirements }\end{array}$ \\
\hline \multirow[t]{4}{*}{ DISC. } & Var.01 & Custody costs of HA & $\sqrt{ }$ & \\
\hline & Var.02 & HA operating expenses & $\sqrt{ }$ & $\sqrt{ }$ \\
\hline & Var.03 & Postponed (deferred) expenses & $\sqrt{ }$ & $\sqrt{ }$ \\
\hline & Var.05 & Allocation and uses of $\mathrm{HA}^{\prime}$ funds & $\sqrt{ }$ & $\sqrt{ }$ \\
\hline \multirow[t]{5}{*}{ NARR. } & Var.04 & Funding resources & & $\sqrt{ }$ \\
\hline & Var.10 & $\begin{array}{l}\text { Restoration, maintenance and } \\
\text { conservation plans }\end{array}$ & $\sqrt{ }$ & \\
\hline & Var.12 & Summary of entities operations & $\sqrt{ }$ & $\sqrt{ }$ \\
\hline & Var.13 & Description and physical condition of HA & $\sqrt{ }$ & $\sqrt{ }$ \\
\hline & Var.14 & Policies and restrictions on $\mathrm{HA}$ & $\sqrt{ }$ & $\sqrt{ }$ \\
\hline \multirow[t]{5}{*}{ PERFO. } & Var.15 & Objective of financial provisions (reserves) & $\sqrt{ }$ & \\
\hline & Var.16 & $\begin{array}{l}\text { Extent financial provisions (reserves) } \\
\text { achieved its objectives }\end{array}$ & $\sqrt{ }$ & \\
\hline & Var.17 & $\begin{array}{l}\text { Financial and managerial performance } \\
\text { compared to previous years }\end{array}$ & $\sqrt{ }$ & \\
\hline & Var.18 & $\begin{array}{l}\text { Variance between budgets and actual } \\
\text { results }\end{array}$ & $\sqrt{ }$ & \\
\hline & Var.19 & Financial summary of the past 5 years & $\sqrt{ }$ & $\sqrt{ }$ \\
\hline \multirow[t]{4}{*}{ ACCOU. } & Var.20 & $\begin{array}{l}\text { Financial capability to cover short term } \\
\text { liabilities }\end{array}$ & $\sqrt{ }$ & \\
\hline & Var.21 & $\begin{array}{l}\text { Financial capability to cover long term } \\
\text { liabilities }\end{array}$ & $\sqrt{ }$ & \\
\hline & Var.22 & Adherence to budget & $\sqrt{ }$ & \\
\hline & Var.23 & Appropriate use for public money & $\sqrt{ }$ & \\
\hline
\end{tabular}

Note: same abbreviations as Tab. 1

\section{Tab. 7: Significance of the FR dimensions}

\begin{tabular}{l|c|c}
\multicolumn{1}{c|}{ Dimension } & $\begin{array}{c}\text { Average } \\
\text { Mean Scores }\end{array}$ & $\begin{array}{c}\text { Relative } \\
\text { Importance Index (RII) }\end{array}$ \\
\hline Accountability & 4.24 & $25.27 \%$ \\
\hline Performance & 4.22 & $25.15 \%$ \\
\hline Disclosure & 4.20 & $25.04 \%$ \\
\hline Narrative & 4.12 & $24.55 \%$ \\
\hline & & $100.00 \%$ \\
\hline
\end{tabular}




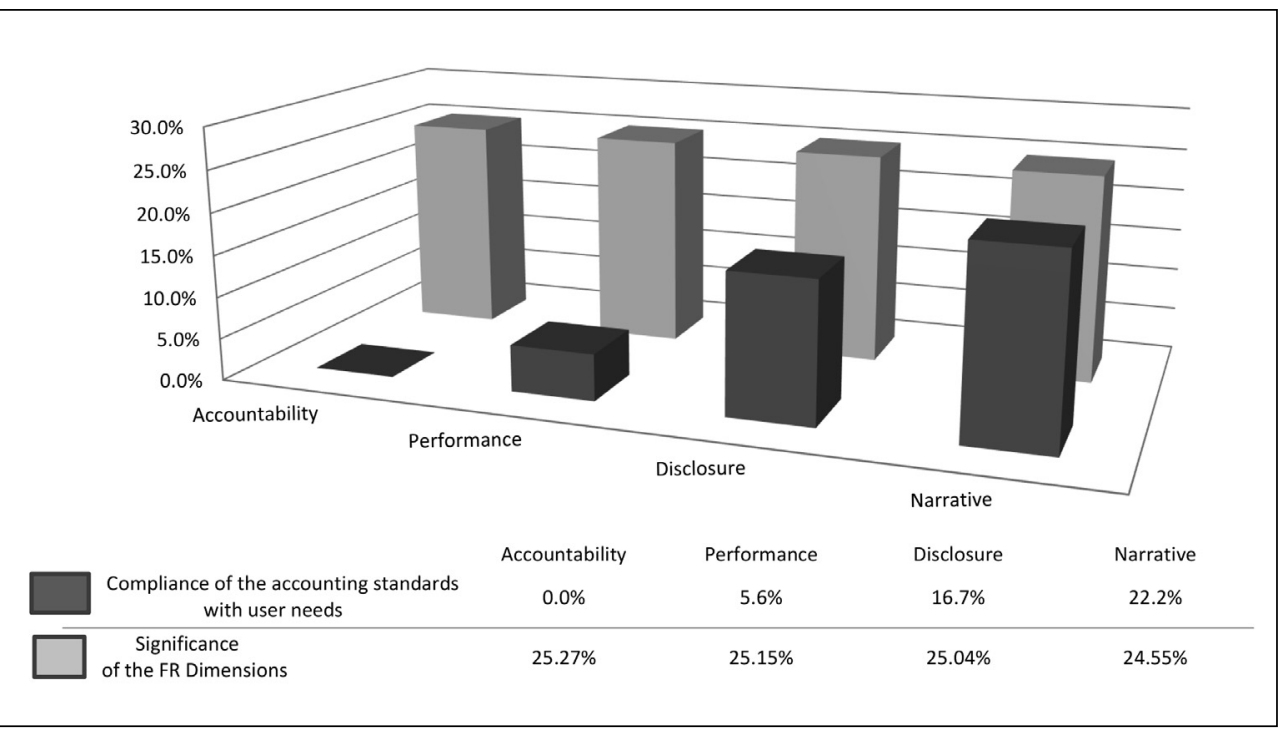

Source: own

average mean score of 4.24 , followed by the performance dimensions with 4.22 while the disclosure and the narrative dimensions scored 4.2 and 4.12 , respectively. The scores of the all the 4 identified and validated FR dimensions are relatively close and high which signifies their importance to HM.

\section{Stage Three: User Needs versus Accoun- ting Standards}

In the current stage, we compare the index dimensions with respect to 1) their significance to $\mathrm{HM}$ and 2) the percentage of compliance of the accounting standards with user-needs. The results of the conducted comparison are demonstrated in (Fig. 5).

The accounting standards requirements are found to comply with only 8 out of the 18 FR information items required by $\mathrm{HM}$, representing $44.4 \%$ of the FR needs of HM needs. Notably, the FR dimensions with highest significance to $\mathrm{HM}$ are the ones that are least required in the accounting standards, namely the performance and the accountability dimensions with a conformity rate of $5.6 \%$ and $0 \%$, respectively, whilst the disclosure and the narrative dimensions acquire the highest conformity rate with user-needs with $16.7 \%$ and $22.2 \%$, respectively. Hence it could be concluded that the accounting standards requirements do not satisfy all FR user-needs but merely some of them.

Based on all previous results, it could be concluded that one of the more significant findings to emerge from this study is that the "Recognition and Measurement" dimension is insignificant to HM in Egypt. The mainstream of the respondents is in the view that the variables underlying this dimension, namely "valuation of HA", "valuation methods of HA" and "cost of valuation of $\mathrm{HA}$ " are rather insignificant to $\mathrm{HM}$. This could be attributed to the fact that it is costly to obtain such kind of information whilst being totally irrelevant to the managerial practice. The qualitative research has clarified the reasons for the opposition of the internal management against all kinds of valuation for $\mathrm{HA}$ :

- Information related to HA valuation and recognition is costly to obtain.

- It is not possible to perform an accurate valuation for history and culture.

- Particularly in Egypt, this kind of information creates a divergence as they oppose the HA Egyptian legislation and bylaws which 
prohibits any kind of sale, or disposal of HA.

The interviewees also shared the same opinion with regard to disposal or depreciation of HA. The intrinsic value of HA does not fall, however old and ruined it is. It is even the case that some HA are considered more valuable when they are older, despite their physical status.

The results of the study resemble the results of other similar studies to a great extant with some variations due to the divergence of the targeted population. A similar study conducted in Italy by Aversano and Christiaens (2014) emphasized that the "valuation methods of HA" and the "cost of valuation of HA" have low significance to FR users. However, the "financial value of HA" had a slightly higher significance. Opt-cit. (2014) targeted politicians and mayors, whilst this study targeted internal management whom conversely the latter information item to be significantly useful in the managerial process. Hence, it could be concluded that the needs of users differ according to their nature.

In reference to the "Disclosure" and "Narrative" dimensions, it is found that the variables related to valuation of $\mathrm{HA}$, estimation of its lifetime, depreciation and idle, namely; Var.06. Var.07, Var.08, Var.09 and Var.11 are "insignificant" to HM. The latter variables are closely related to the recognition and measurement dimension and this justifies why the respondents did not have strong opinion in regard. Managers find that specifying a certain life time or financial value for HA which survived for thousands of years is considered unreasonable. They affirm that HA is not to be assessed based on its physical characteristics but by its uniqueness and historical and cultural associations to present, which is certainly beyond valuation. On the other hand, there has been a consensus on all the variables underlying the "Performance" and "Accountability" dimensions, signifying its importance to HM.

The obtained results are partially in line with Aversano and Christiaens (2014). Optcit. (2014) investigated the elected officials FR of HA needs, whom had an interest in disclosure, narrative and performance information for accountability, decision making and performance measurement purposes. The main difference between the 2 studies is the recognition and measurement dimension which is significant to elected officials and insignificant to HM. This is due to the different nature of the users. The HA managers are more insightful with respect to the nature of $\mathrm{HA}$; they realize that it will never be possible to get accurate financial valuation for HA that surveyed through thousands and thousands of year. In addition the financial valuation of $\mathrm{HA}$ will be useful in the HM (Barton, 2005).

Finally, it could be concluded that the results of the study suggest that the modified accrual is the appropriate basis to be used to account for HA in Egypt. Hence, that the FR information required by users did not include items related to the recognition of HA yet the users affirmed their need information about performance, accountability and deferred expenses. Clearly, the modified accrual is the suitable accounting basis within this context.

\section{Conclusions}

Heritage assets are sought to be safeguarded for its infinite contribution to knowledge and culture. It is the governments' role to ensure the conservation of HA for present and future generations by exercising sound practices of heritage management (HM). Financial reporting plays an essential role in the managerial practice, by providing useful information for the decision making. Existing research on accounting for HA has taken a one dimension perspective which focuses on examining proper FR approaches and neglecting user-needs. Despite that, user-needs research plays a critical role in governmental accounting research. Ouda (2005) affirms that the identification of userneeds is the base for determining FR objectives, which accounting approaches and reporting models are, determined upon. User-needs research helps to develop deep knowledge and understanding of the users and their needs.

Consequently, we aimed to contribute to user-needs research by investigating the FR needs of internal management of heritage related entities. Internal management is an integral group of the internal-users whom are considered the most important user group of governmental financial reports. For this purpose we developed and validated a FR disclosure index that denotes the significant FR information for HM. The index sought to be tested in a country that possesses a bequest of HA; thus, Egypt was selected for its worldfamous legacy of cultural heritage. The objectives of the study were achieved in several 
milestones, which pertain to the research questions. The first milestone pertaining to the investigation of the governmental FR information required by $\mathrm{HM}$ was achieved by means of conducting qualitative and quantitative research. The data was triangulated using multiple data sources (interviews and survey questionnaires), resulting in the identification of $18 \mathrm{FR}$ information items which were found significant for HM. Accordingly, the FR index for $\mathrm{HM}$ was constructed. The second milestone was to determine the most significant FR dimensions to HM. The results have shown the validation of the FR index and the ranking of the FR dimensions based on significance. Finally, the results of the last milestone pertaining to investigating to what extent do the accounting standards requirements satisfy HM's FR needs, revealed that the accounting standards' requirements do not respond to all FR user needs but merely to some of them, thus failing to fulfill the primary function of FR, which is to provide information of use to stakeholders.

In a nutshell, the findings of this research have assisted to identify the user-needs information as imposed in the decisionusefulness model for general purpose financiall reporting in with respect to $\mathrm{HA}$. The results of the empirical investigation revealed that $\mathrm{HM}$ require FR information mostly about performance and accountability, while the FR information related to the valuation and recognition of $\mathrm{HA}$ are found insignificant to the practice. The interviewees imparted the insight that any kind of valuation of HA or estimation of life time and depreciation for HA is considered unrealistic. The intrinsic value of HA does not fall, however old and deteriorated is the condition of the HA.

The validated $\mathrm{FR}$ index for $\mathrm{HM}$ would guide the financial statements preparers to the information required by the users, thus assuring a better utilization of the FR information by the management. The index could be used to assess the quality of FR in annual reports from user-needs perception. It could be used to guide governments to the appropriate approach to account for HA. The evidence from this study would let us suggest that the modified accrual is the appropriate accounting basis for HA in the country context of Egypt. Seeing that the FR information required by users did not include items related to the recognition of HA yet the users affirmed their need information about performance, accountability and deferred expenses. The obtained results are substantiality significant for Egypt, considering that it is in its way to reform its governmental sector. The attained results from this research would help Egypt to save enormous costs associated with the adopting of accrual accounting and the full capitalization approach. Generally, the index should help countries with similar conditions to define the appropriate accounting treatment for $\mathrm{HA}$. This is considered a novel and noteworthy contribution to the literature and practice.

We can also conclude that the needs of FR information of HA differ among the various stakeholders. By comparing our results to those of Aversano and Christiaens (2014), we would find that there are similarities in the needs of politicians and elected officials compared to the needs of internal management with respect to the disclosure dimensions and narrative dimension. However, variations do exist, an exemplar for this is the recognition dimension, which the politicians required further information about and the management overlooked it and where as the accounting standard setters settled in between. An extension for this study would be to conduct an observational research based on the observational theory. Future Research could scrutinize how the information on HA is used in reality by the various stakeholders. This shall also help in analyzing how it impacts the debate between various stakeholders.

The results of this study could be generalized and replicated with due care to similar populations; countries that possess HA and have similar laws such as denying sale or disposal of heritage possessions. Further extension of the research might be to assess the FR requirements of all different users of HA and make comparative analysis. The proposed index should also motivate researchers to conduct comparative studies between countries, e.g. developing versus developed aiming at providing helpful insights and shedding light on variations between countries, which enables suggesting proper HA accounting treatment in different contexts. Most importantly, the results of this study could be used to assess the effectiveness of implemented accounting systems in meeting user-needs, which is considered the main objective of FR.

\section{References}

Abou-Youssef, M., Kortam, W., Abou-Aish, E., \& El-Bassiouny, N. (2011). Measuring 
Islamic-driven buyer behavioral implications: A proposed market-minded religiosity scale. Journal of American Science, 7(8), 728-741.

Accounting Standards Board. (2006). Heritage Assets: Can Accounting do Better? [Discussion Paper]. Retrieved from https://www. iasplus.com/en/publications/migrated/pub904.

Australian Accounting Research

Foundation. (1990). Statement of Accounting Concepts SAC 2 Objective of General Purpose Financial Reporting. Retrieved from http:// membershandbook.charteredaccountants.com.

Aversano, N., \& Christiaens, J. (2014). Governmental financial reporting of heritage assets from a user needs perspective: Governmental Financial Reporting of Heritage Assets. Financial Accountability \& Management, 30(2), 150-174. https://dx.doi. org/10.1111/faam.12032.

Azam, A., Qiang, F., Abbas, S. A., \& Abdullah, M. I. (2013). Structural equation modeling (SEM) based trust analysis of Muslim consumers in the collective religion affiliation model in e-commerce. Journal of Islamic Marketing, 4(2), 134-149. https://dx.doi. org/10.1108/17590831311329278.

Barker, P. (2006). Heritage Assets Can Accounting do Better? Accountancy Ireland, 38(4), 48-50.

Barth, M. E., \& Clinch, G. (1998). Revalued financial, tangible, and intangible assets: Associations with share prices and non-marketbased value estimates. Journal of Accounting Research, 36(supp), 199-233. https://dx.doi. org/10.2307/2491314.

Barton, A. D. (1999). A trusteeship theory of accounting for natural capital assets. Abacus, 35(2), 207-222. https://dx.doi.org/10.1111/14676281.00041.

Barton, A. D. (2000). Accounting for public heritage facilities - assets or liabilities of the government? Accounting, Auditing \& Accountability Journal, 13(2), 219-236. https://dx.doi.org/10.1108/09513570010323434.

Barton, A. (2005). The conceptual arguments concerning accounting for public heritage assets: A note. Accounting, Auditing \& Accountability Journal, 18(3), 434-440. https://dx.doi.org/10.1108/09513570510600774.

Barton, A. (2009). The use and abuse of accounting in the public sector financial management reform program in Australia. Abacus, 45(2), 221-248. https://dx.doi. org/10.1111/j.1467-6281.2009.00283.x.
Beattie, V., Mclnnes, B., \& Fearnley, S. (2004). A methodology for analysing and evaluating narratives in annual reports: A comprehensive descriptive profile and metrics for disclosure quality attributes. Accounting Forum, 28(3), 205-236. https://dx.doi.org/10.1016/j.accfor.2004.07.001.

Buzby, S. L. (1974). Selected items of information and their disclosure in annual reports. The Accounting Review, 49(3), 423-435.

Chin, W. W., \& Todd, P. A. (1995). On the use, usefulness, and ease of use of structural equation modeling in MIS research: a note of caution. MIS quarterly, 19(2), 237-246. https://dx.doi.org/10.2307/249690.

Christiaens, J. (1999). Financial accounting reform in flemish municipalities: An empirical investigation. Financial Accountability \& Management, 15(1), 21-40. https://dx.doi. org/10.1111/1468-0408.00072.

Christiaens, J. (2003). Accrual accounting reforms in Belgian local governments: A comparative examination. Journal of Public Budgeting, Accounting \& Financial Management, 15(1), 92-109. https://dx.doi. org/10.1108/JPBAFM-15-01-2003-B006.

Christiaens, J. (2004). Capital assets in governmental accounting reforms: comparing Flemish technical issues with international standards. European Accounting Review, 13(4), 743-770. https://dx.doi.org/10.1080/096 3818042000237133.

Christiaens, J., Rommel, J., Barton, A., \& Everaert, P. (2012). Should all capital goods of governments be recognised as assets in financial accounting? Baltic Journal of Management, 7(4), 429-443. https://dx.doi. org/10.1108/17465261211272175.

Churchill Jr, G. A. (1979). A paradigm for developing better measures of marketing constructs. Journal of Marketing Research, 16(1), 64-73. https://dx.doi.org/10.2307/3150876.

Coy, D., Dixon, K., Buchanan, J., \& Tower, G. (1997). Recipients of public sector annual reports: theory and an empirical study compared. The British Accounting Review, 29(2), 103-127. https://doi.org/10.1006/bare.1996.0039.

CPA Australia. (2006). CPA Australia's Comments on IPSASB Consultation Paper Accounting for Heritage Assets under the Accrual Basis Accounting. Retrieved from http://www.ifac.org.

Davidson, S. (1977). Financial Reporting by State and Local Government Units. Center 
for Management of Public and Nonprofit Enterprise, Graduate School of Business, University of Chicago.

Daymon, C., \& Holloway, I. (2010). Qualitative research methods in public relations and marketing communications. Routledge.

Egypt State Information System. (n.d.). Retrieved October 14, 2012, from http://www. sis.gov.eg.

Ellwood, S., \& Greenwood, M. (2016). Accounting for heritage assets: Does measuring economic value 'kill the cat'? Critical Perspectives on Accounting, 3(8), 1-13. https://dx.doi.org/10.1016/j.cpa.2015.05.009.

Hair, J. F., Black, W. C., Babin, B. J., Anderson, R. E., \& Tatham, R. L. (2006). Multivariate Data Analysis (6th ed.). Peasron Education International.

Hay, L. E., \& Antonio, J. F. (1990). What users want in government financial reports. Journal of Accountancy, 170(2), 91.

International Council on Monuments and Sites, Australia. (1999). The Burra Charter: the Australia ICOMOS charter for the conservation of places of cultural significance. Retrieved from https://www.icomos.org/en/.

Jones, D. B., Scott, R. B., Kimbro, L., \& Ingram, R. W. (1985). The needs of users of governmental financial reports. Governmental Accounting Standards Board of the Financial Accounting Foundation.

Jones, S., \& Puglisi, N. (1997). The relevance of AAS 29 to the Australian public sector: A cause for doubt? Abacus, 33(1), 115-132. https://dx.doi. org/10.1111/1467-6281.00006.

El Kayaly, D., \& Taher, A. (2010). Developing Benefit-based measurement scale using factor analysis: an improved method for understanding Egyptian car buyers. International Review of Business Research Papers, 6(4), 58-76.

Lacerra, A., \& Stafford, A. (2009). Heritage assets: The UK accounting challenge. In Proceedings from CIGAR 12th biennial conference. Modena: Italy.

Lee, J., \& Fisher, G. (2004). Infrastructure assets disclosure in Australian public sector annual reports. Accounting Forum, 28(4), 349-368. https://dx.doi.org/10.1016/j. accfor.2004.08.002.

Mack, J. (2003). An investigation of the information requirements of users of Australian public sector financial reports. Retrieved from https://eprints.qut.edu.au/15854/1/Janet_ Mack_Thesis.pdf.
Mack, J., \& Ryan, C. (2006). Reflections on the theoretical underpinnings of the general-purpose financial reports of Australian government departments. Accounting, Auditing \& Accountability Journal, 19(4), 592-612. https://dx.doi.org/10.1108/09513570610679146.

Marston, C. L., \& Shrives, P. J. (1991). The use of disclosure indices in accounting research: a review article. The British Accounting Review, 23(3), 195-210. https://dx.doi.org/10.1016/0890-8389(91)90080-L.

Mayston, D. (1992). Capital accounting, user needs and the foundations of a conceptual framework for public sector financial reporting. Financial Accountability \& Management, 8(4), 227-248. https://dx.doi. org/10.1111/j.1468-0408.1992.tb00441.x.

Mignot, H., \& Dolley, C. (2000). Are AAS 29 financial statements useful? Accounting Research Journal, 13(1), 51-61.

NSW Heritage Office and Department of Urban Affairs and Planning. (1996). Conservation Areas, guidelines for managing change in heritage conservation area. Retrieved from http://www.environment.nsw. gov.au/heritage/publications/.

NSW Treasury, New South Wales. (2004). Heritage Assets Management Guideline, Total Asset Management. Retrieved from http://www. environment.nsw.gov.au/.

Ouda, H. A. G. (2005). Transition to Accrual Accounting in the Public Sector of Developed and Developing Countries: Problems and Requirements. With Special Focus on the Netherlands and Egypt. Tilburg University, School of Economics and Management. Retrieved from http://www.sciepub.com/ reference/48735.

Ouda, H. (2014). Towards a Practical Accounting Approach for Heritage Assets: An Alternative Reporting Model for the NPM Practices. Journal of Finance and Accounting, 2(2), 19-33. Retrieved from http://pubs.sciepub. com/jfa/2/2/1/index.html.

Priest, A. N., Ng, J., \& Dolley, C. (1999). Users of local government annual reports: information preferences. Accounting, Accountability \& Performance, 5(3), 49-62.

Productivity Commission. (2006, April 6). Conservation of Australia's Historic places [Productivity Commission Inquiry Report No. 37]. Canberra: Productivity Commission. Retrieved from https://www.pc.gov.au/inquiries/ completed/heritage/report/heritage.pdf. 
Queensland Department of Public Works. (2008). Building asset performance framework: a best practice guideline for the performance assessment of Queensland Government buildings. Retrieved from http://www.hpw.qld. gov.au/SiteCollectionDocuments/BAPF.pdf.

Robbins, W. A. (1984). Consensus between preparers and users of municipal annual reports: an empirical analysis. Accounting and Business Research, 14(54), 157-162. https:// dx.doi.org/10.1080/00014788.1984.9729202.

Rosenblatt, M. (1956). Acentral limit theorem and a strong mixing condition. Proceedings of the National Academy of Sciences, 42(1), 43-47. https://dx.doi.org/10.1073/pnas.42.1.43.

Shan, J. (2006). Speech on Urban Development and Cultural Heritage Conservation in the New Century. In The 2nd International Conference on Heritage Conservation and Sustainable Development. Shaoxing, China.

Sharifabadi, A. A. (2012). The effect of some contingent variables on Universities' Accounting Systems and Performance Management. Retrieved from https://eprints. soton.ac.uk/341516/.

Stanley, T., Jennings, N., \& Mack, J. (2008). An examination of the content of community financial reports in Queensland local government authorities. Financial accountability \& management, 24(4), 411-438. https://dx.doi. org/10.1111/j.1468-0408.2008.00460.x.

Steccolini, I. (2004). Is the annual report an accountability medium? An empirical investigation into Italian local governments. Financial Accountability \& Management, 20(3), 327-350. https://dx.doi.org/10.1111/j.02674424.2004.00389.x.

Sutcliffe, P. (2003). The standards programme of IFAC's public sector committee. Public Money \& Management, 23(1) 29-36. https://dx.doi.org/10.1111/1467-9302.00338.
Trenholm, B., \& Arcelus, F. (1989). Accounting valuation methods: Structuring an unstructured P. Accounting Horizons, 3(3), 82.

Walker, R. G., Dean, G. W., \& Edwards, P. J. (2004). Infrastructure reporting: attitudes of preparers and potential users. Financial Accountability \& Management, 20(4), 351-375. https://dx.doi.org/10.1111/j.14680408.2004.00199.x.

Wild, S. (2013). Accounting for Heritage, Cultural and Community Assets-Alternative Metrics from a New Zealand Māori Educational Institution. Australasian Accounting, Business and Finance Journal, 7(1), 3-22. https://dx.doi. org/10.14453/aabfj.v7i1.2.

Ms. Nabiela Noaman, MBA. Ghent University

Faculty of Economics and Business Administration Department of Public Governance, Management and Finance Belgium

Nabiela.noaman@ugent.be

Prof. Dr. Hassan Ouda, Ph.D. German University in Cairo

Faculty of Management Technology Department of Accounting and Finance Egypt Hassan.ouda@guc.edu.eg

Prof. Dr. Johan Christiaens, Ph.D. Ghent University

Faculty of Economics and Business Administration Department of Public Governance, Management and Finance Belgium Johan.christiaens@ugent.be 


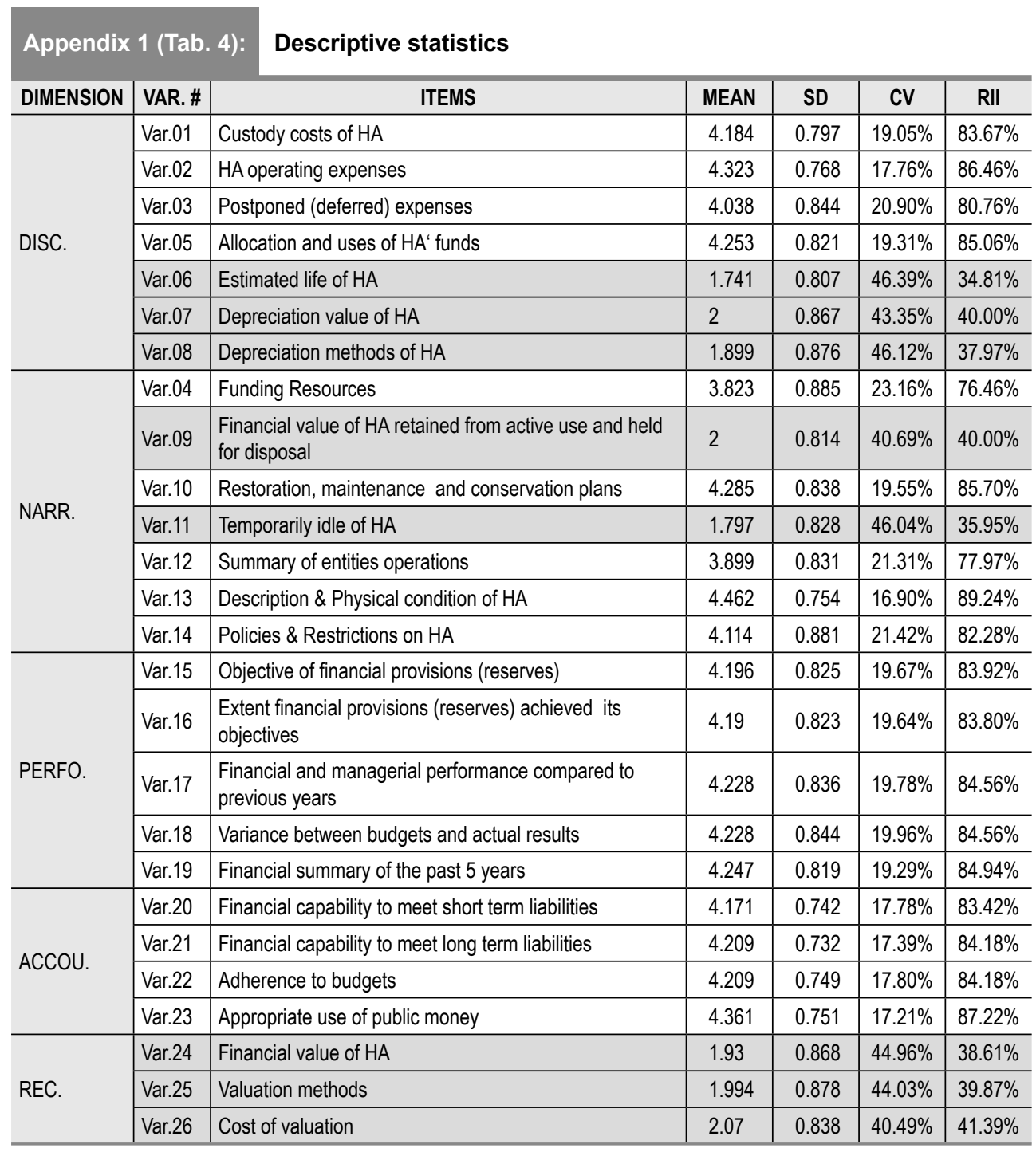

Source: same as Tab. 1

Note: same abbreviations as Tab. 1 
Finance

\begin{tabular}{|c|c|c|c|c|c|c|}
\hline \multirow{2}{*}{$\begin{array}{c}\text { Appendix } 2 \text { (Tab. 8): } \\
\text { Dimension }\end{array}$} & \multicolumn{6}{|c|}{$\begin{array}{l}\text { Confirmatory Factor Analysis (CFA) - regression weights } \\
\text { at standardized regression weights }\end{array}$} \\
\hline & Var. & Estimate & S.E. & C.R. & $\mathbf{P}$ & $\begin{array}{c}\text { Standardized } \\
\text { Regression Weights }\end{array}$ \\
\hline \multirow{4}{*}{ Accountability } & Var.23 & 0.853 & 0.057 & 14.846 & $* \star *$ & 0.8 \\
\hline & Var.22 & 0.95 & 0.048 & 19.959 & $* * *$ & 0.892 \\
\hline & Var.20 & 1 & & & & 0.948 \\
\hline & Var.21 & 0.997 & 0.038 & 26.032 & $* * *$ & 0.958 \\
\hline \multirow{5}{*}{ Performance } & Var.19 & 1 & & & & 0.937 \\
\hline & Var.15 & 1.032 & 0.040 & 26.127 & $* * *$ & 0.96 \\
\hline & Var.18 & 1.056 & 0.040 & 26.113 & $\star \star \star *$ & 0.96 \\
\hline & Var.16 & 1.031 & 0.039 & 26.306 & $* * *$ & 0.962 \\
\hline & Var.17 & 1.051 & 0.039 & 26.675 & $* \star *$ & 0.964 \\
\hline \multirow{4}{*}{ Disclosure } & Var.05 & 0.764 & 0.088 & 8.667 & $* * *$ & 0.638 \\
\hline & Var.03 & 0.879 & 0.087 & 10.084 & $* * *$ & 0.714 \\
\hline & Var.01 & 1 & & & & 0.861 \\
\hline & Var.02 & 1.009 & 0.075 & 13.446 & $* * *$ & 0.902 \\
\hline \multirow{5}{*}{ Narrative } & Var.04 & 1 & & & & 0.517 \\
\hline & Var.12 & 1.165 & 0.216 & 5.401 & $* \star *$ & 0.641 \\
\hline & Var.10 & 1.211 & 0.221 & 5.489 & $* * *$ & 0.661 \\
\hline & Var.14 & 1.277 & 0.232 & 5.495 & $* * *$ & 0.663 \\
\hline & Var.10 & 1.278 & 0.217 & 5.877 & $\star * *$ & 0.775 \\
\hline
\end{tabular}

Source: same as Tab. 1

Note: same abbreviations as Tab. 1 


\title{
Abstract
}

\section{INDEXING FINANCIAL REPORTING INFORMATION FOR HERITAGE MANAGEMENT}

\author{
Nabiela Noaman, Hassan Ouda, Johan Christiaens
}

The main role of effective heritage management $(H M)$ is to utilize heritage assets while safeguarding them for present and future generations. Proper financial reporting could increase the management capacity in safeguarding these valuable possessions by providing useful information for decision making and management discharge of accountability. In this study we focus on investigating the significance of financial reporting information for the HM practice. We assess how accounting standards comply with user-needs. For this purpose, a measurement tool; disclosure index is developed to identify and assess the significance of financial reporting information for HM. The index is tested quantitatively and qualitatively in Egypt for its huge bequest of heritage. Our results indicate that four financial reporting dimensions of HA; namely performance, accountability, disclosure and narrative are significant for HM, comprising 18 financial reporting items. While the recognition and measurement dimension is found insignificant to the managerial practice. On the international context, the study contributes to the current debate; "determining the appropriate accounting treatment for heritage assets". This is by identifying user-needs which is the base for determining financial reporting objective. On the country context of Egypt, the results revealed that the appropriate accounting basis for HA is the modified accrual.

Key Words: Public sector accounting, accounting standards, financial reporting, heritage management, disclosure index, user-needs, Egypt.

JEL Classification: H2, H83, M41, M48, Z19.

DOI: 10.15240/tul/001/2018-2-013 